\title{
Examining psychosocial and physical hazards in the Ghanaian mining industry and their implications for employees' safety experience
}

\author{
Amponsah-Tawiah, K., Jain, A., Leka, S., Hollis, D., \& Cox, T. (2013). Examining psychosocial and \\ physical hazards in the Ghanaian mining industry and their implications for employees' safety \\ experience. Journal of Safety Research, 45, 75-84.
}

Author revised manuscript - pre-publication version.

\begin{abstract}
In addition to potentially hazardous conditions environment that are prevalent in mines, there are various physical and psychosocial risk factors which have the potential to affect mine workers' safety and health. Without due diligence to mine safety these risk factors can affect workers' safety experience, in terms of near misses, disabling injuries and accidents experienced or witnessed by workers. This study sets out to examine the effects of physical and psychosocial risk factors on workers' safety experience in a sample of Ghanaian miners. 307 participants from five large scale mining companies producing three different mineral products (gold, manganese and bauxite) responded to a cross sectional survey examining physical and psychosocial hazards in the Ghanaian mining industry and their implications for employees' safety experience. Results from zero-inflated poisson regression models indicated that mining conditions, equipment, ambient conditions, support and security and work demands and control as being significant predictors of near misses, disabling injuries and accidents experienced or witnessed by workers. The type of mine where participants worked had important implications for workers' safety experience with non-gold mine workers reporting a better safety experience than their colleagues from gold mining companies.
\end{abstract}

Key words: safety experience, physical and psychosocial risks, mining, developing country, stress, injury

\section{Introduction}

The combination of a conducive market for commodities, the availability of investment capital for both exploration and project development, and the significant geological endowment of West Africa, have created momentum for several new mining ventures in the sub-region (WAMF, 2008). Ghana is one such country in the West-African sub-region, which has become a preferred destination for mineral sector investment with the legal mining industry contributing over $49 \%$ of the country's Gross foreign exchange earnings in 2010 (Owiredu, 2011). This increase in investment and mining activity, however, presents not only economic opportunities for the country but also major challenges, particularly in the area of occupational safety and health for employees in the sector. This has also been seen in other countries, where due to the lucrative export value of the minerals produced, there are high performance pressures and time constraints that are often to the detriment of mining operations safety levels (Masia \& Pienaar, 2011).

Mining is globally recognised as one of the most hazardous sectors (ILO, 2010) and also considered by mine workers as more dangerous and hazardous than workers in other sectors (Gyekye, 2003). Furthermore, coinciding with the potentially hazardous environment, conditions and equipment prevalent in mines, there are various physical and psychosocial risk factors which have the potential to affect mine workers' safety and health and without due diligence to mine safety these plethora of risk factors can affect workers' safety experience, i.e. number of near misses, disabling injuries and accidents experienced or witnessed by workers (Pule, 2011). This study therefore sets out to examine the effects of physical and psychosocial risk factors on workers' safety experience in a sample of Ghanaian miners.

\section{Impact of hazards in the physical work environment on safety experience}

The dynamic nature of mining and the constant tampering of soil and rocks present both a direct and perceived threat to workers' safety (Pule, 2011) since they are exposed to a number of hazardous 
conditions in the physical work environment which include excessive noise, mine gases, mine fires, heat stress, poor visibility and dusty conditions. These hazards in turn can lead to accidents which vary across the mining sector and include rock fall, fires, explosions, mobile equipment accidents, falls from height, entrapment and electrocution (Donoghue, 2004).

Noise is ubiquitous within mining, stemming from a variety of increasingly mechanised practices, including boring, drilling, blasting, cutting, materials handling, ventilation, crushing, conveying and ore processing (Donoghue, 2004). Across this range of practices, McBride (2004) found exposure to noise ranged from $88 \mathrm{db}$ to $117 \mathrm{db}$, and concluded that without sufficient ear defence equipment there is wide scope for noise induced hearing loss. In addition to the well documented physiological effects of noise, Chau et al's., (2009) study showed that hearing impairment was a risk factor for the worker and their colleagues as it prevented the affected from hearing various sounds and warning messages. In addition hearing disability has been found to affect workers' orientation and balance, which increases the susceptibility for falls of those afflicted (Gauchard et al., 2006). Furthermore, higher db levels can increase levels of fatigue and impair the efficiency of worker performance (Leka \& Jain, 2010). Due to the precariousness of the mine environment, the requirement for workers' awareness, alertness and cognisance of the risks mines pose is vital for both their own and their colleagues' safety experience.

However, as McBride (2004) notes, although exposure to noise is a significant occupational mining hazard, conditions in the mining can have a greater impact on the safety experience of mine workers. For example, Sutherland's (2011) seven year review of Ghanaian Ashanti gold miners' acute traumatic injuries (which resulted in more than three days absence from work, a loss of consciousness, or death) showed that the overwhelming cause of injury $(58.4 \%)$ was from moving or falling objects. Likewise, Aidoo and Eshun's (2012) three year analysis of occupational injury records in Ghanaian mines also found that ground fall and slip falls were major causes of accidents. Additionally they found the most common physical risk factors for injuries to workers legs, hands and heads were caused by faulty machinery, electrocution and vehicular accidents.

Restricted space as occurs in most underground mines also greatly limits the number and type of mechanical devices (cranes, hoists, or forklifts) that can be used to reduce physical workload hence causing workers to sometimes work beyond their limits. Workers in mines with very low roofs may have to work on their hands and knees, backs or stomachs in confined spaces, risking the possibility of an explosion or cave-in, electric shock or exposure to harmful gasses. In fact, restricted spaces in many underground mines practically compel workers to adopt awkward postures that ergonomists strive to avoid (Torma-Krajewski et al., 2006). Workers in surface mines, on the other hand also have to contend with rigid outdoor work in all kinds of weather and climates. Surface mining, which is also more commonly associated with solar heat or cold temperatures, has the associated risks of heat stroke or chill. Heat exhaustion is also a risk factor in underground mining due to the dual effect of increasing rock temperature and the auto-compression of the air chamber (Donoghue et al., 2000).

Physical work demands in both underground and surface mines pose several challenges. Chau et al. (2009) explored the association between workers' self-reported level of exposure to physical job demands in their work in the period up until their last occupational injury across a randomly selected sample of 2888 workers across a variety of roles and sectors in North Eastern France. They assessed a wide range of 14 physical job demands (for example, use of pneumatic tools, use of other vibrating hand tools, use of hammers, use of machine tools, work on vibrating platforms, manual handling tasks, awkward postures, high pace of work, work in adverse climate) and found that increased exposure to physical job demands generated an increased injury risk, particularly for older workers (i.e. those aged over 45). This finding extends Chau et al.'s (2005) study which showed the accumulation of high physical job demands generates fatigue which exacerbates disability and increases the risk of injury. Interestingly, the array of physical job demands Chau et al., (2009) chose are synonymous with manual labour and are all considered requisite in mine work.

While dust is omnipresent in mining culminating from the incessant breaking of rocks and extraction of soil, it poses another significant hazard. The occupational health literature is replete with accounts of the short and long term effects of dust on the respiratory system (Pule, (2011), however it can also have shorter term implications which affect worker safety, through the blurring of vision and irritation to workers' skin. While the impact of hazards in the physical environment has been the focus on most research in this area, psychosocial hazards are also known to have an impact on safety experience; however such research in the mining sector is scarce. 


\section{Impact of psychosocial hazards on safety experience}

Psychosocial hazards are defined by the International Labour Organisation (1986) in terms of the interactions among job content, work organisation and management, and other environmental and organisational conditions, on the one hand, and the employees' competencies and needs on the other that prove to have a hazardous influence over employees' health through their perceptions and experience (ILO, 1986). A simpler definition of psychosocial hazards might be those aspects of the design and management of work, and its social and organisational contexts that have the potential for causing psychological or physical harm (Cox \& Griffiths, 2005). There is reasonable consensus in the literature of the nature of psychosocial hazards which are characterised by factors such as job content, workload and work place, work schedule, control, environment and equipment, organisational culture and function, interpersonal relationships at work, role in origination, career development and home - work interface (Cox, 1993).

Higher psychological job demands have been associated with higher levels of unsafe work behaviour (Hofmann \& Stetzer, 1996), more frequent near-misses (Elfering et al., 2006) and a higher likelihood of work place injuries (Chmiel, 2005). More specifically, excessive workload has been shown to compromise workplace safety outcomes (Turner et al., 2010). As Hansez and Chmiel (2010) note, previous research has shown that when there is a tendency to prioritise production-related goals over safety goals, there is a greater propensity for workplace injuries, with the risk of injury exacerbated greatly in the context of hazardous work events. Masia and Pienaar (2011) posit that within the mining industry managers' preoccupation with production targets means that many workers have little control over their work practices or pace, with employers (many of whom are authoritarian in management style) directing their employees to engage in unsafe practices by taking shortcuts.

Interpersonal and managerial support for safety is an important factor to consider as it is associated with lower levels of negative safety outcomes such as workplace injuries (Turner et al., 2010). When managers, supervisors and co-workers articulate and enact the importance of working safely, they reinforce safe practices and teach employees the value of working safely through vicarious learning. Such practices also provide workers with social cues which they use to understand expectations about their behaviour. These cues are particularly important in circumstances where there is a conflict in priorities between production and safety.

Alper and Karsh's (2009) review of the safety violations literature in occupational health and safety found that violations had several psychosocial antecedents, with the outcome of violations being the increased risk of accidents. Similar to Zohar and Luria's (2005) findings, they found that workers' perceptions of their organisation's safety climate was shaped by the policy and procedural actions of top management and the supervisory actions exhibited by shop floor or frontline supervisors. When workers perceived their superiors condoned violations there was an increased risk of violations and subsequent increased risk of accidents. Similarly, Ghosh et al. (2004) found that when supervisory support for health and safety was low, with a preoccupation on workers achieving production targets, workers' health and safety behaviours altered.

Alper and Karsh (2009) also found that lack of support stemmed not only from superiors but also from lack of worker support in the systems of work implemented, the organisation, the environment, the task itself and the tools and technologies used to accomplish the task, which were all shown to influence workers' propensity to violate safety. In terms of the nature of the task, when workers are under time pressure with an emphasis on quicker ways of working to save time, when they have multiple conflicting demands and when they are conducting work which has the potential to be physically exhausting they are more likely to enact safety violations. Pule (2011) notes how mining is associated with long and awkward hours which, coupled with the intense physical demands of the work, can result in worker fatigue and can affect workers' safety experience.

Wadsworth et al., (2003) studied the associations and interactions between the level of psychosocial risk factors, for example, job demand, decision latitude and social support (Karasek, 1979); intrinsic effort, extrinsic effort and reward dimensions (Siegrist, 1996), temporal risk factors (for example, long, unsociable hours; unpredictable hours night work, shift work) and physical risk factors (for example, noise, harmful substances and fumes), and workers' risk of accidents. The findings showed an approximate linear increase in accident risk with level of exposure to negative occupational factors; 
however the results did not delineate how the constituent risk factors were specifically related to accident risk or negative safety experience. However, Swaen et al.'s, (2004) study did measure demand risk factors explicitly. In a longitudinal study of 7051 workers in the Netherlands, they found that of the 108 who had experienced an occupational accident, high psychological job demands and emotional demands were found to be risk factors.

Wellens and Smith (2011) elaborated on Wadsworth et al.'s, (2003) research by assessing how cumulative exposure to a combination of psychosocial, temporal and physical workplace risk factors were related to the occurrence of occupational accidents within a sample of 12,500 workers across 3 studies. Their findings showed that low levels of decision latitude and low levels of reward were both associated with occupational accidents. Across all studies they found that the co-occurrence of physical hazards and temporal stressors had a greater significant association with occupational accidents than the predictive predictor of each risk factor separately. When analysing results by job type, across all studies a significant association was found between manual occupations and occupational accidents, which the authors inferred was due to a combination of the increased prevalence of physical hazards and the temporal organisation of working hours in the 'blue- collar' sector.

While, Wellens and Smith (2011) concluded that psychosocial factors have only a minor contributory role in occupational accidents, there is some disparity in their findings when compared to Alper and Karsh's (2009) and Swaen et al.'s (2004) studies. In addition, Wellens and Smith's (2011) classification of hours worked and shift patterns as temporal stressors rather than psychosocial risk factors influenced their conclusion (working hours, time pressure, shift patterns are widely acknowledged as psychosocial risk factors see for e.g. Cox, 1993; Cox, Griffiths, \& Rial-Gonzalez, 2000; WHO, 2003; Leka \& Jain, 2010).

Thus, further clarification and elucidation of how psychosocial risk factors in tandem with physical risk factors affect the safety experience of workers is required. This need is particularly heightened in mining sector in developing countries, where restrictions of access mean there is a paucity of knowledge about these associations.

\section{Research questions}

This study therefore aims to examine the effects of physical and psychosocial risk factors on mine workers' safety experience by seeking to answer the following research questions:

- To what extent do job and organisational characteristics predict the risk of workers' safety experience, i.e. number of near misses, disabling injuries and accidents experienced or witnessed by workers?

- To what extent do physical risk factors predict the risk of workers' safety experience, i.e. number of near misses, disabling injuries and accidents experienced or witnessed by workers?

- To what extent do psychosocial risk factors predict the risk of workers' safety experience, i.e. number of near misses, disabling injuries and accidents experienced or witnessed by workers?

\section{Methodology}

The nature of this study to a large extent was multidisciplinary. As such a combination of research methods, both qualitative and quantitative, was employed for a fuller investigation of the research questions.

\subsection{Procedure}

Initial semi-structured interviews (Massarik, 1981) were conducted with 35 key stakeholders in the Ghanaian mining industry. Participants were nine managers in charge of health, safety and environment in nine different mining companies, nine managers in charge of community relations, one manager in charge of corporate social responsibility, nine union executives from the different companies, a manager at the Ghanaian Chamber of Mines, two principal inspectors of mines at the Minerals Commission, an executive member of the mine workers union responsible for health safety and environmental issues in the mines, an executive officer of a community based mining advocacy organisation, a manager of an international $\mathrm{NGO} / \mathrm{CSO}$ and a contractor/supplier to the mining industry. The rationale for targeting key personnel at the interface of identified stakeholder 
organisations stems from leadership theories, which describe effective leaders as managing from the boundary (Druskat \& Wheeler, 2003). Thus these participants holding key positions are satisfactory sources of information regarding the policies and operations of their organisations. Information gathered through the interviews provided the basis for the design of a quantitative study and further offered a qualitative context to the quantitative data collected. The quantitative study involved the administration of a survey to a sample of employees from large scale mining companies. This paper presents findings from the quantitative study only.

\subsection{Sample}

A mixed method sampling strategy (Teddlie \& Yu, 2007), which is a combination of the probability and non-probability sampling techniques, was used to select 330 participants from nine large scale mining companies. The purposive sampling technique was used to select large scale mining companies operating in the minerals sector for more than four years. This was achieved through the effective collaboration of the Ghana Chamber of Mines. Nine companies operating in Ghana met the selection criteria. Since the researchers also wanted to examine the health and safety trends between the various mineral producing companies selected purposively, the stratified sampling technique was further used to group them into two strata (i.e., gold and non-gold producing companies); three gold companies and two non-gold mining companies were selected. Participants were then randomly selected by using stratified random sampling technique during tool-box briefings before the commencement of work. All mine employees attended the tool-box briefings and were stratified on the basis of pattern of work, role in the organisation (technical or administrative). Due to small cohorts, managers and female employees were excluded from the sample. The selected participants were administered the questionnaire survey to complete and return to the researchers. Questionnaires were anonymous and participants were assured of strict confidentiality and anonymity of their responses and treatment of the information they provided according to the Data Protection Act (1998). Ethical approval of the study was gained by the Ethics Committee of the University of Nottingham.

A total of 330 questionnaires were administered to selected participants. The companies cut across three different mineral products (i.e., gold, bauxite and manganese). Out of the 330 questionnaires administered, 307 of them were correctly completed and returned representing a response rate of $93 \%$. The high response rate was basically due to the administration procedure adopted. This meant that participants did not have the flexibility of deferring their responses to a later date, a situation which accounts for low return rate in most questionnaire surveys. The distribution of responses across the mining companies is presented in Table 1.

$51.5 \%$ of respondents fell within the age range of $26-40$ years, while $33.9 \%$ fell within the ages of 41 50 years. $64.5 \%$ worked in non-gold mines (bauxite and manganese) while $35.5 \%$ worked in gold mines. Just over $70 \%$ of the participants had technical roles and were involved with mining operations while the others had administrative roles. Over $50 \%$ of the participants had more than 5 years of experience in their current role. Table 2 presents the sample characteristics.

\section{INSERT TABLE 1 and TABLE 2 HERE}

\subsection{Data analysis}

Data from the questionnaire survey were coded manually by assigning values to the various responses and entered into SPSS v19.0 for descriptive data analysis. To refine and reduce the large numbers of related items to manageable variables for use in the multivariate analysis an exploratory factor analysis (EFA) (Costello \& Osborne, 2005) using the principal components analysis (PCA) method was conducted to identify the underlying factors because of its simplicity and distinctive characteristic of data-reduction capacity for factor extraction. The Kaiser-Meyer-Olkin (KMO) measure of sampling adequacy and Barlett's test of sphericity were used to examine the appropriateness of factor analysis for the factor extraction. The KMO statistic varies between 0 and 1 and for a satisfactory factor analysis to proceed, the KMO value should be greater than the acceptable threshold of 0.5 , as a value closer to 1 indicates that patterns of correlations are relatively compact as a result of which the factor analysis would yield distinct and reliable factors (Kaiser, 1974).

PCA allows for data reduction and is regarded as a useful tool for determining the interdependence of items (Thompson, 2004). Eigenvalues were used to assist in determining the appropriate number of 
factors. Factor loadings were analyzed by using the varimax factor rotation method so as to interpret latent items underlying a factor. Items with factor loadings of .5 or greater were grouped and judgments made on their applicability to an underlying concept. Extracted items comprising a construct were examined by Cronbach's alpha for internal consistency. A Cronbach's alpha score of 0.7 or higher is usually regarded as indicative of good internal reliability (Costello \& Osborne, 2005).

The STATA statistical package, version 11.0 SE was used to carry out multivariate analysis and examine the research questions. Zero-inflated poisson regression was carried out for investigating the relationship of job characteristics, psychosocial hazards and physical hazards in the workplace (independent variables) on worker injury, accident - no injury, near misses and accidents witnessed (dependent variables). Although the standard poisson regression model provides a valid framework for analyzing the safety experience data, it offers no explanation for the large number of participants with no reported accidents, injuries or near misses. The zero-inflated regression method integrates results from logit and Poisson models to adjust predicted incidence for the probability of a variable always having zero cases (Long and Freese, 2001). In this study, the exposure to psychosocial hazards and physical hazards was used in the logit model to investigate if the level of problems posed by these hazards could explain a lack of reported accidents/injuries/near misses. Vuong tests were used to confirm the choice of the zero-inflated model over standard poisson regression (Vuong, 1989), where this was not confirmed standard poisson regression was carried out. Overall model goodness of fit was judged by the log-likelihood chi-squared statistic. The regression coefficients were reported as Incidence Rate Ratios (IRR). The significance level was set at $a=0.05$.

\subsection{Measures and factor analysis}

The questionnaire was constructed on the basis of the literature and responses from the qualitative study to explore psychosocial and physical hazards in large scale mining industries in Ghana and their impact on employees' safety experience. Principal component analysis with varimax rotation was conducted on the psychosocial hazard scale, physical hazard scale and on the items relating to safety experience.

Demographic characteristics: These included questions on age, department, tenure, pattern of work and type of mineral produced.

Physical Hazards: This section of the questionnaire was developed by the research team on the basis of the literature and qualitative and observational research conducted prior to the quantitative study. Items on the physical hazard scale included mine gases, mine fires, excessive noise, heat stress, poor visibility and dusty conditions. These were assessed on a five-point likert scale ranging from most problematic (5) to least problematic (1). The KMO measure of sampling adequacy of for these items was 0.730 , which was well above the acceptable threshold and the Bartlett's Test of Sphericity (chi-square value $=1004.080, \mathrm{df}=66$ ) and the associated significance level ( $p$-value $=0.000$ ), indicated that the correlation matrix was not an identity matrix. Principal component analysis conducted on the physical hazard scale revealed three components (Eigenvalue $>1$ ), as presented in Table 3: mining equipment ( $\alpha=.77)$, ambient conditions $(\alpha=.69)$ and mining conditions $(\alpha=.66)$, the internal reliability for each of the extracted variables was considered acceptable.

\section{INSERT TABLE 3 HERE}

Psychosocial Hazards: This section of the questionnaire was developed on the basis of existing a validated instrument and qualitative and observational research conducted prior to the quantitative study. Items on the psychosocial hazard scale were derived from the short version of the Copenhagen Psychosocial Questionnaire (COPSOQ) (Kristensen et al, 2005). It included six items on high workload, lack of job security, poor colleague support, poor supervisory support, lack of job control and lack of role clarity to assess psychosocial hazards. Participants were asked to rate the items on a five-point likert scale from most prevalent (5) to least prevalent (1). The KMO measure of sampling adequacy of for these items was 0.758 , which was well above the acceptable threshold and the Bartlett's Test of Sphericity (chi-square value $=581.976, \mathrm{df}=15$ ) and the associated significance level $(p$-value $=0.000)$, indicated that the correlation matrix was not an identity matrix. Principal component analysis conducted on the psychosocial hazard scale revealed two factor components (Eigenvalue $>1)$, as presented in Table 4: support \& security $(\alpha=.74)$, and work demands \& control $(\alpha=.72)$. The internal reliability was each of the extracted variables was considered acceptable. 


\section{INSERT TABLE 4 HERE}

Personal safety experience: Workers' personal safety experience has been referred to as the number of near misses, disabling injuries and accidents experienced or witnessed by workers (Pule, 2011). Items assessing the safety experience of participants therefore included: the number of accidents and near misses, disabling injuries and accidents witnessed where participants were asked to indicate the frequency of their experience, in the last one year, on a five point scale ranging from 0 to 4 or more. The KMO measure of sampling adequacy of for these items was 0.729 , which was well above the acceptable threshold and the Bartlett's Test of Sphericity (chi-square value $=561.461, \mathrm{df}=15$ ) and the associated significance level $(p$-value $=0.000)$, indicated that the correlation matrix was not an identity matrix. The principal component analysis yielded four factor components (Eigenvalue $>1$ ), as presented in Table 5. These four variables were worker injury outcomes, and single item measures for accident but no injury, near misses and accidents witnessed. Items on the worker injury outcomes scale showed an internal reliability of $\alpha=.73$.

\section{INSERT TABLE 5 HERE}

\section{Results}

The zero-inflated poisson regression models examining the relationship of job characteristics, psychosocial hazards and physical hazards in the workplace (independent variables) on near misses, accidents witnessed, worker injury outcomes and incidence of accident with no injury were statistically significant and the Vuong tests confirmed the choice of the zero-inflated model over standard Poisson regression, except in the case of accident with no injury, where the standard poission was a better fit as compared to the zero-inflated model. The results are summarized in Table 6.

\subsection{Hazards and near misses}

All physical and psychosocial hazards were positively associated with incidence of near misses. Worse mining conditions (IRR: $1.38,95 \% \mathrm{Cl}: 1.14-1.63$ ), ambient conditions at the mines (IRR: 1.54 , $95 \% \mathrm{Cl}: 1.25-1.89$ ), the mining equipment used (IRR: $1.24,95 \% \mathrm{Cl}: 1.06-1.46)$ as well as higher work demands but low control (IRR: $1.30,95 \% \mathrm{Cl}: 1.07-1.57$ ) and low support and security (IRR: $1.59,95 \%$ $\mathrm{Cl}: 1.39-1.92)$ were more likely to increase the incidence of near misses, clearly indicating that poor working conditions in the mines were linked to poor safety experience of the workers. Mining conditions and support and security were also significant predictors in the logistic portion of the model, where poorer mining conditions $\exp (-2.13)$ and low support and security $\exp (-1.11)$ decreased the likelihood for reporting zero near misses.

Type of mine (IRR: $0.55,95 \% \mathrm{Cl}: 0.36-0.82$ ) was negatively associated with incidence of near misses, indicating that workers in gold mines compared to workers in non-gold mines, while holding the other variable constant in the model, were $45 \%$ more likely to report the incidence of near misses.

\subsection{Hazards and accidents witnessed}

Only ambient conditions at the mines were significantly associated with the number of times a worker witnessed an accident in which either they or one of their colleagues was injured. Worse ambient conditions at the mines (IRR: $1.83,95 \% \mathrm{Cl}: 1.17-2.88$ ), were more likely to increase the incidence of accidents witnessed, indicating that poor ambient conditions in the mines characterized by excessive noise, heat stress, dusty conditions and poor visibility were linked to poor safety experience of the workers. Work demands and control was a significant predictor in the logistic portion of the model, where higher work demands but low control exp(-0.47) decreased the likelihood for reporting zero accidents witnessed.

Type of mine (IRR: $0.39,95 \% \mathrm{Cl}: 0.21-0.70$ ) was negatively associated with incidence of near misses, indicating that workers in gold mines compared to workers in non-gold mines, while holding the other variable constant in the model, were $61 \%$ more likely to report the incidence of near misses.

\subsection{Hazards and worker injury outcomes}


Only mining conditions were significantly associated with the number of times a worker was injured. Worse mining conditions (IRR: $1.18,95 \% \mathrm{Cl}$ : 1.01-1.41), were more likely to increase the incidence of accidents leading to injury, indicating that poor mining conditions in the mines characterized by poor ventilation, mine gases, and higher risk of mine fires were linked to poor safety experience of the workers in terms of injury outcomes. Mining conditions were also a significant predictor in the logistic portion of the model, where worse mining conditions $\exp (-0.73)$ decreased the likelihood for reporting zero worker injury outcomes.

\subsection{Hazards and incidence of accidents with no injury}

Both psychosocial hazards were positively associated with the number of times that a worker was actually involved in an accident but without any injury. Higher work demands but low control (IRR: 1.84, 95\% Cl: 1.36-2.47) and low support and security (IRR: $1.63,95 \% \mathrm{Cl}: 1.45-1.90$ ) were more likely to increase the incidence of accidents with no injury, clearly indicating that poor psychosocial working conditions in the mines were linked to poor safety experience of the workers.

\section{Discussion}

The research questions addressed in this study relate to how psychosocial and physical risk factors impact upon the safety experience, i.e. number of near misses, disabling injuries and accidents, experienced or witnessed by workers within the Ghanaian mining industry.

The experience of injuries, accidents and near misses was associated with mining conditions. In addition, witnessed accidents were associated with ambient conditions in the mines. With regards to the conditions of workplaces affecting safety outcomes, in the most comprehensive meta-analysis of the safety literature to date, Nahrgang et al., (2010) found physical risks and hazards impeded workers progress towards working safely and explained the largest percentage of variance for adverse safety events (84.8\%) and accidents and injuries (50\%) across all of the industries sampled. This finding is in accordance with DeJoy et al., (2004) who found that physical risks and hazards such as noise, heat, dust, chemicals and hazardous tools and equipment are negatively related to employee involvement in safety activities.

Mining equipment was also found to have a negative effect on the safety experience of employees in terms of near misses. To be efficient in production and meet mineral quotas, heavy machinery is a necessity within the modern mining sector. If not 'fit for purpose' these machines have the potential to pose a direct threat to mine workers' safety. Within all mine types, accidents relating to the haulage system used constitute the second greatest hazard (Dhillon, 1998). There has been a growing trend for parent multinational companies to dump their obsolete equipment (which has been outlawed in countries with more stringent regulations on machine safety) in developing countries such as Ghana. Such modern day equipment has become more complex and sophisticated and requires a high degree of skill to operate and maintain economically, effectively and safely. The use of insecure and faulty equipment also generates excessive noise and exhales dust particles into the mine environment. As previously outlined, these factors can impinge upon workers' safety experience by obstructing workers' ability to hear and understand safety signals and to be aware of approaching danger (for example, a reversing on-site vehicle), all of which contribute to the workers' cognitive load and increase the likelihood of safety errors occurring.

The results showed that workers with high workloads, unclear roles and responsibilities over which they have little or no control reported experiencing more near misses (but not other outcomes such as accidents and injuries) compared to workers with clear and reasonable work demands over which they have adequate control. This finding partly concurs with previous research which has showed a direct relationship between job demands and safety outcomes as higher workload has been associated with more negative safety-related events (Evans et al., 2005; Frone, 1998; Nahrgang et al., 2010). In addition, role overload which was also considered in this analysis and is one facet of job demands (Turner et al., 2010) was associated with reporting of more near misses. The present findings are in accordance with prior research which has found that role overload adversely affects workers' safety compliance and can be a detriment to safe working (e.g., Barling et al., 2002; Hofmann \& Stetzer, 1996; Wallace \& Chen, 2005; Zohar, 2000). Reporting of near misses was also found to be associated with poor support from colleagues and supervisors and lack of job security. 
The importance of both support and job security have been well supported in the literature (e.g. Goldenhar et al., 2003; Lauver et al., 2009; Probst, 2004; Probst and Brubaker, 2001).

Another interesting finding was that the type of mine showed a significant negative relationship with workers' safety experience, with employees in the gold mines reporting witnessing more accidents and experiencing more near misses than their counterparts in the non-gold sector (i.e., manganese and bauxite companies). There are many plausible reasons for this finding. Firstly, more gold sector employees participated in this study than non-gold sector employees, thus it is reasonable to expect that the probability for gold workers to have had an accident to be higher. Secondly, at the time the study was administered, companies in the non-gold sector were experiencing production declines and so their level of output was not as rigorous as companies in the gold sector. Thirdly, the level of labour intensity is higher in the gold sector as the extraction methods are more laborious and exhaustive than non-gold sector techniques.

Another potential finding for the disparity in safety experience between the gold sector and non-gold sector companies is that one of the two non-gold mining companies had signed up to the occupational health and management standard OHSAS 18001 in comparison to one out of the seven gold mining companies. The fundamental objective of OHSAS 18001 is to support and promote good practice in the area of occupational health and safety via systematic and structured management (FernándezMuniz et al., 2012). As Chang and Liang (2009) note, organisations that have adopted and implemented this certification have been assessed to have an adequate safety management system in place to control occupational risk and demonstrate higher levels of management commitment, safety training, worker involvement in safety, safety communication and feedback, safety rules and procedures, safety promotion policies and safety behaviour more so than non-certified organisations (Vinodkumar \& Bhasi, 2011).

The outcomes emanating from adopting and implementing the standard include the potential to reduce both accidents and interruptions in the production process and the enhancement of the firm's compliance with legal obligations, its internal climate and image, and its overall performance (Chang and Liang, 2009; Sánchez Toledo et al., 2009). However, implementation of the standard in isolation is not sufficient, and firms must have in situ a favourable safety climate both vertically and laterally throughout the organisational hierarchy to be able to achieve the above outcomes (Fernández-Muniz et al., 2012).

Thus, within the present study, it is reasonable to infer that on a balance of scale, the benefits accrued to the non-gold sector as a result of the show of commitment to occupational health and safety are more likely to outweigh those derived by the gold mining companies. However, a larger and more proportionate sample of certified and non-certified firms would be required to test this empirically. Another issue to be kept in mind is that OHSAS 18001 has been criticised for not covering psychosocial risks effectively in terms of providing detailed guidance on how to deal with them (Leka et al., 2011) even though it refers to them. However, as the standard does provide a framework to manage any type of risk to workers' health and safety in a systematic way, it makes sense to assume that those companies that are certified in implementing OHSAS will show a higher level of awareness and commitment to occupational health and safety management in general.

\section{Limitations}

The use of a single-source self-report data in the study may be subject to common method variance issues. In spite of this shortcoming, previous studies do indicate that self-report measures of wellbeing and quality of life are related to independent observations of these variables (Lusk et al., 1995). Another limitation is the small sample size and the use of cross-sectional data which limits the extent to which causal inferences can be made. With regard to worker safety experience responses, worker perceptions after suffering a work injury may influence their perceptions of organizational factors. Retrospective data collection, though common, is a limitation in safety studies that examines occupational injury outcomes, including near misses (Clarke, 2006). An additional limitation associated with retrospective data collection is with accident and injury recall, especially over the 12month time frame. It is also possible that safety experience could have been affected by the respondents' work history during the 12-month time period for which they were to recall near misses, accidents and injuries. However, it was ensured that all respondents had been working the entire 12 months, had not changed jobs, but may have been promoted or demoted or may have worked 
differing hours than what was collected. Despite these limitations, this study serves as a starting point towards developing further initiatives in this area, as it is one of the few studies addressing both physical and psychosocial hazards in relation to employee safety experience in the Ghanaian mining industry.

\section{Conclusion}

In considering the three aims a mining company should strive for outlined at the outset of this paper, the physical and psychosocial risks identified and the associations found indicate that production efficiency and economic gain may come at the expense of worker safety. With regards to the physical hazard associations found, interventions should be pitched at the primary level to eliminate the rogue not 'fit for purpose' machinery used at source as stated within Article 7 (a) of the ILO Safety and Health in Mines Convention, 1995 (No.176). Safety management control systems should also be in place (as stated in Article 6 of the same Convention). Though this would not guarantee the cessation of work injuries and adverse safety events entirely, it would reduce the potential for workplace injuries and the subsequent perception of threat.

High job demands and low control over workload were associated with negative safety reported outcomes. Thus, management and supervisors should be aware of these possible effects and aim at achieving a balance between work demands, control of work pace and workload and outputs. This would also afford workers the opportunity to be more aware of and attentive to their own safety compliant behaviour (Vinodkumar \& Bhasi, 2011). As Fernández-Muniz et al., (2012) note, within firms with OHSAS 18001 accreditation, it is the internationalisation of, commitment to and communication of the standard rather than the standard per se which influence safety levels. It is encouraging that two of the nine firms sampled had adopted the standard; however it has to be embodied within their work practices.

As a final point, it is worth noting that in revisiting a mining company's principle aims, rather than being viewed in isolation and ostracised, there is clear evidence that the safety of workers is inextricably linked not only to their working conditions but also to their employing firm's productivity and economic performance. It is of utmost importance that a comprehensive risk management framework is implemented, addressing both physical and psychosocial hazards, to promote a positive safety and health experience and a competitive position in the global market. 


\section{References}

Aidoo, S.J., \& Eshun, P.A. (2012). Time Series Model of Occupational Injuries Analysis in Ghanaian Mines-A Case Study. Research Journal of Environmental and Earth Sciences, 4(2), 162-165.

Alper, S.J., \& Karsh, B.T. (2009). A systematic review of safety violations in industry. Accident Analysis and Prevention, 41, 739-754.

Barling, J., Loughlin, C. A., \& Kelloway, E.K. (2002). Development and test of a model linking safetyspecific transformational leadership and occupational safety. Journal of Applied Psychology, 87, 488496.

Chang, J.I., \& Liang, C.L. (2009). Performance evaluation of process safety management systems of paint manufacturing facilities. Journal of Loss Prevention in the Process Industries, 22, 398-402.

Chau, N., Ravaud, J.F., Otero-Sierra, C., Legras, B., Macho-Fernandez, J., Guillemin, F., Sanchez, J., \& Mur, J.M. (2005). Prevalence of impairments and social inequalities: A community-based study in Lorraine. Rev Epidemiol Sante Publique, 53, 614-628.

Chau, N., Bhattacherjee, A., Kunar B. M., \& Lorhandicap Group. (2009). Relationship between job, lifestyle, age and occupational injuries. Occupational Medicine, 59, 114-119.

Chmiel, N. (2005). Promoting healthy work: Self-reported minor injuries, work characteristics, and safety behaviour. In C. Korunka \& P. Hoffman (Eds.), Change and quality in human service work. Munchen \& Mering: Rainer Hampp Verlag.

Costello, A.B., \& Osborne, J.W. (2005). Best practices in exploratory factor analysis: four recommendations for getting the most from your analysis. Practical Assessment, Research \& Evaluation, 10 (7), 1-9.

Clarke, S. (2006). The relationship between safety climate and safety performance: A meta-analytic review. Journal of Occupational Health Psychology, 11(4), 315-327.

Cox, T. (1993). Stress Research and Stress Management: Putting Theory to Work. Sudbury: HSE Books.

Cox, T., \& Griffiths, A. (2005). The nature and measurement of work-related stress. In: J. Wilson, N., Corlett, (Eds), Evaluation of Human Work: A Practical Ergonomics Methodology. 3rd ed., (pp. 553573). Boca Raton, FL: CRC Press.

Cox, T., Griffiths, A., \& Rial-Gonzalez, E. (2000). Research on work related stress. Report by the European Agency for Safety and Health at Work. Luxembourg: Office for Official Publications of the European Communities.

DeJoy, D.M., Schaffer, B.S., Wilson, M.G., Vandenberg, R.J., \& Butts, M.M. (2004). Creating safer workplaces: assessing the determinants and role of safety climate. Journal of Safety Research, 35, 81-90.

Dhillon, B.S. (1998). Mining equipment reliability, maintainability, and safety. London: Springer.

Donoghue, A.M., Sinclair, M.J., \& Bates, G.P. (2000). Heat exhaustion in a deep underground metalliferous mine. Occupational and Environmental Medicine, 57(3), 165-174.

Donoghue, A.M., (2004). Occupational health hazards in mining: an overview. Occupational Medicine, 54, 283-289.

Druskat, V.U., \& Wheeler, J.V. (2003). Managing from the boundary: The effective leadership of selfmanaging work teams. Academy of Management Journal, 46, 435-457. 
Elfering, A., Semmer, N., \& Grebner, S. (2006). Work stress and patient safety: Observer-rated work stressors as predictors of characteristics of safety-related events reported by young nurses. Ergonomics, 49, 457-469.

Evans, D.D., Michael, J.H., Wiedenbeck, J.K., \& Ray, C.D. (2005). Relationships between organizational climates and safety-related events at four wood manufacturers. Forest Products Journal, 55(6), 23-28.

Ferguson, E., \& Cox, T. (1993). Exploratory factor analysis: a user's guide. International Journal of Selection and Assessment, 1, 84-94.

Fernández Mũ̃iz, B., MontesPeón, J.M., \& Vázquez Ordás, C.J. (2012). Safety climate in OHSAS 18001certified organisations: Antecedents and consequences of safety behaviour. Accident Analysis and Prevention, 45, 745-758.

Frone, M.R. (1998). Predictors of work injuries among employed adolescents. Journal of Applied Psychology, 83, 565-576.

Gauchard, G.C., Deviterne, D., Guillemin, F., Sanchez, J., Perrin, P.P., Mur, J.M., Ravaud, J.F., \& Chau, N. (2006). Prevalence of sensory and cognitive disabilities and falls, and their relationships: a community-based study. Neuroepidemiology, 26, 108-118.

Ghosh, A.K., Bhattacherjee A., \& Chau N. (2004). Relationships of working conditions and individual characteristics with occupational injuries: A case-control study in coal miners. Journal of Occupational Health, 46, 470-478.

Goldenhar, L.M., Williams, L.J., \& Swanson. N.G. (2003). Modelling relationships between job stressors and injury and near-miss outcomes for construction labourers. Work and Stress, 17(3), 218240.

Gyekye, S.A. (2003). Causal attributions of Ghanaian industrial workers for accident occurrence: Miners and non-miners perspective. Journal of Safety Research, 34, 533- 538.

Hansez, I., \& Chmiel, N. (2010). Safety behaviour: Job demands, job resources, and perceived management commitment to safety. Journal of Occupational Health Psychology, 15, 267-278.

Hofmann, D.A, \& Stetzer, A. (1996). A cross level investigation of factors influencing unsafe behaviours and accidents. Personnel Psychology, 49, 307-339.

International Labour Organization (ILO) (1995). Safety and Health in Mines Convention (C 176). http://www.ilo.org/ilolex/english/convdisp1.htm (Accessed on 1 March 2012).

International Labour Organization (ILO) (2010). Mining: a hazardous work. Geneva: International Labour Organization.

International Labour Organization (ILO) (1986). Psychosocial factors at work: Recognition and control. Report of the Joint International Labour Office and World Health Organization on Occupational Health, Ninth Session, Geneva, 18-24 September 1984. Occupational Safety and Health Series No. 56. Geneva: International Labour Office.

Karasek, R.A. (1979). Job demands, job decision latitude and mental strain: implications for job redesign. Administrative Science Quarterly, 24, 285-308.

Kaiser, H. (1974). An index of factorial simplicity. Psychometrika, 39, 32-36.

Lauver, K.J., Lester, S., \& Le, H. (2009). Supervisor support and risk perception: their relationship with unreported injuries and near misses. Journal of Managerial Issues, 21(3), 327-343.

Leka, S., \& Jain, A. (2010). Health Impact of Psychosocial Hazards at Work: An overview. Geneva: World Health Organization. 
Leka, S., Jain, A., Widerszal-Bazyl, M., Żolnierczyk-Zreda, D., \& Zwetsloot, G. (2011). Developing a standard for psychosocial risk management: PAS1010. Safety Science, 49(7), 1047-1057.

Ledesma, A.S-T.,Muñiz, B.F., Peón, J.M.M, \& Ordás, C.J.V. (2009). Spanish survey reveals motivations, obstacles and benefits of OHSAS 18001 certification. ISO Management System, 4, 3640.

Long, J., \& Freese, J. (2001). Predicted probabilities for count models. STATA Journal, 1, 51-57.

Lusk, S.L., Kerr, M.J., \& Baer, L.M. (1995). Psychometric testing of the reduced Laffrey Health Conception Scale. American Journal of Health Promotion, 9, 220-225.

Masia, U., \& Pienaar, J. (2011). Unravelling safety compliance in the mining industry: examining the role of work stress, job insecurity, satisfaction and commitment as antecedents. SA Journal of Industrial Psychology, 37(1), Art\#937, 10 pages. http://dx.doi.org/10.1402/sajip.v37i1.937 (Accessed on 1 March 2012).

Massarik, F. (1981). The interviewing process re-examined. In P. Reason \& J. Rowan (Eds.), Human inquiry: A sourcebook of new paradigm research (pp.201-206). Chichester, U.K.: Wiley.

McBride, D.I. (2004). Noise-induced hearing loss and hearing conservation in mining. Occupational Medicine, 54 (5), 290-296.

Nahrgang, J.D., Morgeson, F.P., \& Hofman, D.A. (2010). Safety at work: a meta-analytic investigation of the link between job demands, job resources, burnout, engagement, and safety outcomes. Journal of Applied Psychology, 96(1), 71-94.

OHSAS Project Group (2007). OHSAS 18001:2007 - Occupational health and safety management systems requirements. London: British Safety Institution.

Owiredu, D. (2011). Annual chamber of mines presidential review. 83rd Annual General Meeting of the Ghana Chamber of Mines. www.ghanachamberofmines.org (Accessed on 1 March 2012).

Probst, T.M. \& Brubaker, T.L. (2001). The effects of job insecurity on employee safety outcomes: cross-sectional and longitudinal explorations. Journal of Occupational Health Psychology, 6(2), 139159.

Probst, T.M. (2004). Safety and Insecurity: Exploring the Moderating Effect of Organizational Safety Climate. Journal of Occupational Health Psychology, 9(1), 3-10.

Pule, T. (2011). Mining activities and occupational health and safety at work. African Newsletter on Occupational Health and Safety, 21(1), 4-7.

Siegrist, J. (1996). Adverse health effects of high-effort/low-reward conditions. Journal of Occupational Health Psychology, 1, 27-41.

Sutherland, D.K.B (2011). Occupational injuries in a gold mining company in Ghana. African Newsletter on Occupational Health and Safety, 21(1), 8-10.

Swaen, G.M.H., van Amelsvoort, L.P.G.M., Bültmann, U., Slangen, J.J.M., \& Kant I.J. (2004). Psychosocial work characteristics as risk factors for being injured in an occupational accident. Journal of Occupational and Environmental Medicine, 46, 521-527.

Teddlie, C., \& Yu, F. (2007). Mixed methods sampling: A typology with examples. Journal of Mixed Methods Research, 1, 77-100.

Thompson, B. (2004). Exploratory and confirmatory factor analysis: understanding concepts and applications (1st Edition). Washington: American Psychological Association. 
Torma-Krajewski, J., Steiner, L., Lewis, P., Gust, P., \& Johnson, K. (2006). Ergonomics and mining: charting a Path to a Safer Workplace. U.S. Department of Health and Human Services, CDC, NIOSH, Publication No. 2006-141. Washington D.C.: NIOSH

Turner, N., Chmiel, N., Hershcovis, M.S., Walls, M. (2010). Life on the Line: Job Demands, Perceived Co-Worker Support for Safety, and Hazardous Work Events. Journal of Occupational Health Psychology, 15(4), 482-493.

Vinodkumar, M.N., \& Bhasi, M. (2011). A study on the impact of management system certification on safety management. Safety Science, 49, 498-507.

Vuong, Q. (1989). Likelihood Ratio Tests for model selection and non-nested hypothesis. Econometrica, 57(2), 307-333.

Wadsworth, E.K.J., Simpson, S.A., Moss, S.C., \& Smith, A.P. (2003). The Bristol stress and health study: accidents, minor injuries and cognitive failures at work. Occupational Medicine, 53, 392-397.

Wallace, J.C., \& Chen, G. (2005). Development and validation of a work-specific measure of cognitive failure: Implications for occupational safety. Journal of Occupational and Organizational Psychology, 78, 615-632.

West Africa Mining Forum (WAMF) (2008). Joint Agency Statement by the African Development Bank, Agence Française de Développement, ECOWAS, WAEMU, and the World Bank on the Occasion of the West Africa Regional Mining Forum in Conakry, Guinea on February 11-12, 2008. http://siteresources.worldbank.org/INTOGMC/Resources/336099-

1204142303639/WAMF statement Eng final.pdf (Accessed on 1 March 2012).

Wellens, B. \& Smith, A.P. (2011). Combined effects of psychosocial factors, working hours and physical agents on accidents at work. In M. Anderson (Ed.), Contemporary Ergonomics and Human Factors (pp.14-21). London: CRC Press - Taylor \& Francis Group.

World Health Organization (WHO). (2003). Work Organization and Stress. Geneva: World Health Organization.

Zohar, D. (2000). A group-level model of safety climate: Testing the effect of group climate on microantecedents in manufacturing jobs. Journal of Applied Psychology, 85, 587-596.

Zohar, D., \& Luria, G. (2005). A multilevel model of safety climate: cross-level relationships between organization and group level climates. Journal of Applied Psychology, 90(4), 616-628. 
Table 1. Distribution of responses across the mining companies

\begin{tabular}{|l|l|l|l|}
\hline Type of mine & $\begin{array}{l}\text { Distributed } \\
\text { Questionnaires }\end{array}$ & $\begin{array}{l}\text { Analysed } \\
\text { Questionnaires }\end{array}$ & Response Rate \\
\hline Gold mining company 1 & 60 & 59 & $98.33 \%$ \\
\hline Gold mining company 2 & 90 & 81 & $90 \%$ \\
\hline Gold mining company 3 & 60 & 58 & $96.67 \%$ \\
\hline Manganese mining company & 60 & 51 & $85 \%$ \\
\hline Bauxite mining company & 60 & 58 & $96.67 \%$ \\
\hline Total & $\mathbf{3 3 0}$ & $\mathbf{3 0 7}$ & $\mathbf{9 3 . 0 3} \%$ \\
\hline
\end{tabular}

Table 2. Sample characteristics and descriptives

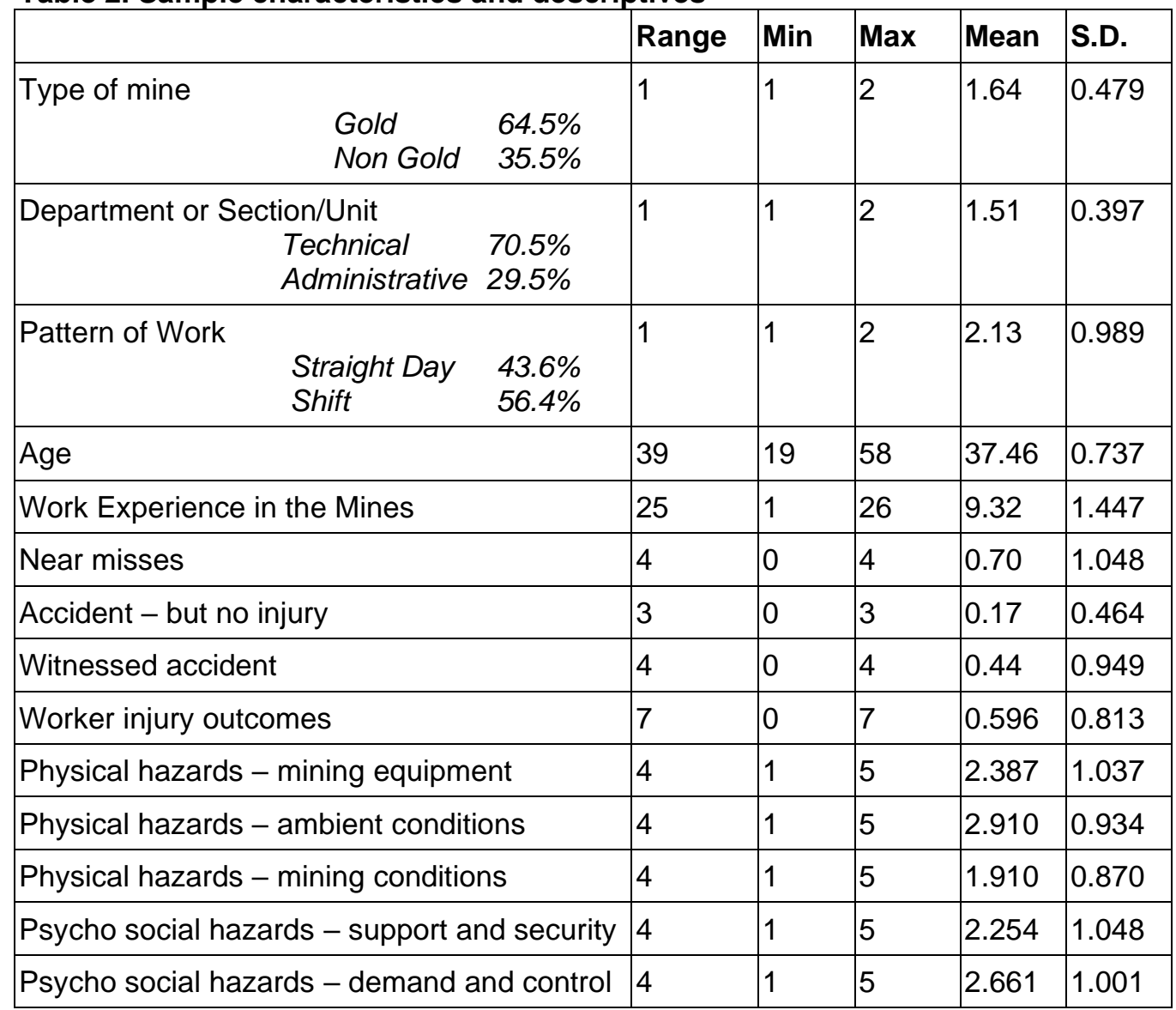

Note: Valid $N=307$

Table 3. Varimax rotation of three factor solution for physical hazard items

\begin{tabular}{|l|l|l|l|}
\hline Item & Component & \multicolumn{2}{l|}{} \\
\hline & $\begin{array}{l}\text { Mining } \\
\text { equipment }\end{array}$ & $\begin{array}{l}\text { Ambient } \\
\text { conditions }\end{array}$ & $\begin{array}{l}\text { Mining } \\
\text { conditions }\end{array}$ \\
\hline Mine gases & & & 0.721 \\
\hline Excessive noise & & 0.681 & \\
\hline Mine fires & & & 0.701 \\
\hline Heat stress & & 0.648 & \\
\hline Dusty conditions & & 0.664 & \\
\hline Use of machinery & 0.833 & & \\
\hline
\end{tabular}




\begin{tabular}{|l|l|l|l|}
\hline Hand tools & 0.819 & & \\
\hline Poor ventilation & & & 0.637 \\
\hline Dangerous driving & 0.684 & & \\
\hline Poor visibility & & 0.693 & \\
\hline$\%$ of variance explained & $23.09 \%$ & $20.47 \%$ & $17.14 \%$ \\
\hline Cronbach's Alpha & 0.77 & 0.69 & 0.66 \\
\hline
\end{tabular}

Note: Only loadings above .5 are displayed

Table 4. Varimax rotation of two factor solution for psychosocial hazard items

\begin{tabular}{|l|l|l|}
\hline Item & Component \\
\hline & $\begin{array}{l}\text { Support and } \\
\text { security }\end{array}$ & $\begin{array}{l}\text { Work demands \& } \\
\text { control }\end{array}$ \\
\hline Poor support from colleagues & 0.888 & \\
\hline Poor support from supervisors & 0.841 & \\
\hline Lack of job security & 0.603 & \\
\hline Unreasonably high workload & & 0.802 \\
\hline Unclear roles and responsibilities & & 0.794 \\
\hline Lack of control over work tasks and pace of work & & 0.682 \\
\hline \% of variance explained & $35.73 \%$ & $31.43 \%$ \\
\hline Cronbach's Alpha & 0.74 & 0.72 \\
\hline
\end{tabular}

Note: Only loadings above.5 are displayed

Table 5. Varimax rotation of four factor solution for safety experience items

\begin{tabular}{|c|c|c|c|c|}
\hline \multirow[t]{2}{*}{ Item } & \multicolumn{4}{|c|}{ Component } \\
\hline & \begin{tabular}{|l|} 
Worker \\
injury \\
outcomes
\end{tabular} & $\begin{array}{l}\text { Accident } \\
- \text { but no } \\
\text { injury }\end{array}$ & $\begin{array}{l}\text { Near } \\
\text { misses }\end{array}$ & $\begin{array}{l}\text { Witnesse } \\
\text { d } \\
\text { accident }\end{array}$ \\
\hline $\begin{array}{l}\text { Number of times you were injured and spent more } \\
\text { than } 3 \text { workdays off work }\end{array}$ & 0.715 & & & \\
\hline $\begin{array}{l}\text { Number of times you were injured at work but } \\
\text { without workdays lost }\end{array}$ & 0.850 & & & \\
\hline $\begin{array}{l}\text { Number of times you remained out of work for 1-3 } \\
\text { days after being injured at work }\end{array}$ & 0.821 & & & \\
\hline $\begin{array}{l}\text { Number of times that you were actually involved in } \\
\text { an accident but without any injury }\end{array}$ & & 0.898 & & \\
\hline $\begin{array}{l}\text { Numbers of times that you nearly missed an } \\
\text { accident }\end{array}$ & & & 0.949 & \\
\hline $\begin{array}{l}\text { Number of times you witnessed an accident in } \\
\text { which any one or more of your colleagues were } \\
\text { injured }\end{array}$ & & & & 0.884 \\
\hline$\%$ of variance explained & $32.89 \%$ & $20.01 \%$ & $17.88 \%$ & $17.55 \%$ \\
\hline Cronbach's Alpha & 0.73 & & & \\
\hline
\end{tabular}

Note: Only loadings above .5 displayed 
Table 6. Zero-inflated Poisson regression models for near misses, accidents witnessed, worker injury outcomes and accident - no injury in Ghanaian mines

\begin{tabular}{|c|c|c|c|c|c|c|c|c|c|c|c|c|c|c|c|c|c|c|c|c|}
\hline & \multicolumn{5}{|c|}{ Near Misses } & \multicolumn{5}{|c|}{ Accidents Witnessed } & \multicolumn{5}{|c|}{ Worker Injury Outcomes } & \multicolumn{5}{|c|}{ Accident - No Injury a } \\
\hline $\begin{array}{l}\text { Vuong (zip vs. } \\
\text { standard Poisson) }\end{array}$ & \multicolumn{5}{|c|}{$z=3.66 \operatorname{Pr}>z=0.000$} & \multicolumn{5}{|c|}{$z=3.89 \operatorname{Pr}>z=0.000$} & \multicolumn{5}{|c|}{$z=4.15 \operatorname{Pr}>z=0.000$} & \multicolumn{5}{|c|}{$\mathrm{z}=1.61 \mathrm{Pr}>\mathrm{z}=0.072$} \\
\hline $\begin{array}{l}\text { Non-zero incident } \\
\text { probability state as } \\
\text { poisson function }\end{array}$ & IRR & $z$ & $P>z$ & \multicolumn{2}{|c|}{$\begin{array}{l}95 \% \\
\text { Confidence } \\
\text { Interval } \\
\end{array}$} & IRR & $z$ & $P>Z$ & \multicolumn{2}{|c|}{$\begin{array}{l}95 \% \\
\text { Confidence } \\
\text { Interval } \\
\end{array}$} & IRR & $z$ & $P>z$ & \multicolumn{2}{|c|}{\begin{tabular}{|l|}
$95 \%$ \\
Confidence \\
Interval
\end{tabular}} & IRR & $z$ & $P>Z$ & \multicolumn{2}{|c|}{$\begin{array}{l}95 \% \\
\text { Confidence } \\
\text { Interval }\end{array}$} \\
\hline Age & 0.75 & -1.90 & 0.057 & 0.55 & 1.01 & 0.70 & -1.68 & 0.094 & 0.47 & 1.06 & 0.91 & -0.31 & 0.753 & 0.51 & 1.63 & 0.86 & -0.67 & 0.502 & 0.55 & 1.33 \\
\hline Type of mine & 0.55 & -2.93 & 0.003 & 0.36 & 0.82 & 0.39 & -3.12 & 0.002 & 0.21 & 0.70 & 0.70 & -1.06 & 0.291 & 0.36 & 1.36 & 0.92 & -0.24 & 0.814 & 0.45 & 1.87 \\
\hline Job function & 1.40 & 1.54 & 0.124 & 0.91 & 2.15 & 1.45 & 1.24 & 0.216 & 0.80 & 2.62 & 1.41 & 1.00 & 0.319 & 0.72 & 2.79 & 1.79 & 1.47 & 0.141 & 0.82 & 3.87 \\
\hline Tenure & 0.99 & -0.16 & 0.871 & 0.85 & 1.15 & 1.24 & 1.98 & 0.058 & 1.00 & 1.54 & 1.10 & 0.70 & 0.481 & 0.85 & 1.42 & 1.18 & 1.38 & 0.168 & 0.93 & 1.48 \\
\hline Pattern of work & 1.15 & 1.41 & 0.158 & 0.95 & 1.38 & 1.01 & 0.05 & 0.957 & 0.78 & 1.29 & 1.21 & 1.01 & 0.313 & 0.84 & 1.75 & 1.32 & 1.49 & 0.137 & 0.92 & 1.89 \\
\hline Mining equipment & 1.24 & 2.65 & 0.008 & 1.06 & 1.46 & 1.00 & 0.02 & 0.980 & 0.79 & 1.27 & 0.97 & -0.15 & 0.883 & 0.64 & 1.48 & 1.10 & 0.64 & 0.520 & 0.82 & 1.50 \\
\hline Ambient conditions & 1.54 & 4.11 & 0.000 & \begin{tabular}{|l|}
1.25 \\
\end{tabular} & 1.89 & 1.83 & 2.62 & 0.009 & 1.17 & 2.88 & 0.93 & -1.87 & 0.071 & 0.79 & 1.22 & 1.06 & 0.31 & 0.756 & 0.74 & 1.51 \\
\hline Mining conditions & 1.38 & 2.54 & 0.011 & 1.14 & 1.63 & 0.78 & -1.69 & 0.092 & 0.58 & 1.04 & 1.18 & 1.39 & 0.012 & 1.01 & 1.41 & 1.84 & 3.99 & 0.000 & 1.36 & 2.47 \\
\hline Support and security & 1.59 & 4.47 & 0.000 & 1.39 & 1.92 & 1.15 & 0.69 & 0.488 & 0.77 & 1.73 & 1.26 & 0.95 & 0.341 & 0.78 & 2.05 & 1.63 & 2.57 & 0.010 & 1.45 & 1.90 \\
\hline $\begin{array}{l}\text { Work demands \& } \\
\text { control }\end{array}$ & 1.30 & 2.71 & 0.007 & 1.07 & 1.57 & 0.82 & -1.29 & 0.198 & 0.61 & 1.11 & 0.91 & -0.45 & 0.651 & 0.62 & 1.35 & 1.18 & 0.99 & 0.321 & 0.85 & 1.65 \\
\hline $\begin{array}{l}\text { Zero } \quad \text { incident } \\
\text { probability state as } \\
\text { logistic function }\end{array}$ & Coef & Z & $P>z$ & $\begin{array}{l}95 \% \\
\text { Confid } \\
\text { Interva } \\
\end{array}$ & & Coef & $z$ & $P>z$ & $\begin{array}{l}95 \% \\
\text { Confid } \\
\text { Interva } \\
\end{array}$ & ce & Coef & $z$ & $P>Z$ & $\begin{array}{l}95 \% \\
\text { Confic } \\
\text { Interv }\end{array}$ & $\begin{array}{l}\text { dence } \\
\text { al }\end{array}$ & & & & & \\
\hline Mining equipment & 0.21 & 0.73 & 0.465 & -0.35 & 0.77 & -0.38 & -1.65 & 0.100 & -0.84 & 0.07 & -0.32 & -0.99 & 0.324 & -0.95 & 0.31 & & & & & \\
\hline Ambient conditions & -0.01 & -0.04 & 0.972 & -0.62 & 0.60 & 0.12 & 0.43 & 0.666 & -0.43 & 0.67 & -0.49 & -1.55 & 0.121 & -1.11 & 0.13 & & co & pared & the & zero \\
\hline Mining conditions & -1.11 & -2.35 & 0.019 & -2.04 & -0.18 & 0.00 & 0.00 & 0.999 & -0.47 & 0.47 & -0.73 & -2.63 & 0.008 & -1.28 & -0.19 & & ह & & & \\
\hline Support and security & -2.13 & -4.24 & 0.000 & -3.11 & -1.14 & 0.35 & 1.21 & 0.228 & -0.22 & 0.93 & 0.36 & 1.32 & 0.187 & -0.18 & 0.90 & & & & & \\
\hline $\begin{array}{l}\text { Work demands \& } \\
\text { control }\end{array}$ & 0.47 & 1.35 & 0.176 & -0.21 & 1.16 & -0.47 & -2.10 & 0.036 & -0.91 & -0.03 & 0.00 & -0.02 & 0.985 & -0.51 & 0.50 & & & & & \\
\hline Model fit data & $\begin{array}{l}\mathrm{N}=3 \\
=18 \\
\mathrm{LR} C \mathrm{C} \\
\log \\
\mathrm{P}<0 .\end{array}$ & $\begin{array}{l}\text { 307; No } \\
\text { 35; Int } \\
\text { hi-squa } \\
\text { likelif } \\
.01\end{array}$ & $\begin{array}{l}\text { ero } n \\
\text { ion } m \\
=62 . \\
\text { d }\end{array}$ & $\begin{array}{l}\text { 122; } \\
\text { del }\end{array}$ & $\begin{array}{r}\text { ero } n \\
\text { logit } \\
05.90\end{array}$ & $\begin{array}{l}\mathrm{N}=3 \\
236 ; \\
\text { LR C } \\
\text { Log li } \\
P<0 .\end{array}$ & $\begin{array}{l}07 \text {; No } \\
\text { Inflat } \\
\text { hi-squa } \\
\text { kelihoo } \\
.05\end{array}$ & $\begin{array}{l}\text { onzero } r \\
\text { ion } m \\
\text { are }=24 \\
d=24\end{array}$ & $\begin{array}{l}=71 \\
\text { del } \\
0 \\
83\end{array}$ & $\begin{array}{l}\text { Eero } n= \\
=\quad \text { logi }\end{array}$ & $\begin{array}{l}\mathrm{N}=3 \\
=26 \\
\mathrm{LR} C \mathrm{C} \\
\log \\
\mathrm{P}<0\end{array}$ & $\begin{array}{l}07 ; \mathrm{N} \\
9 ; \mathrm{In} \\
\text { hi-squ } \\
\text { likeli } \\
.01\end{array}$ & $\begin{array}{l}\text { nzero } n \\
\text { ation } m \\
\text { are }=23 \\
\text { ood }\end{array}$ & $\begin{array}{l}=38 \\
\text { odel } \\
84 \\
=\end{array}$ & $\begin{array}{r}\text { Zero } n \\
=\quad \text { logit } \\
64.84\end{array}$ & $\begin{array}{l}N=3 \\
\text { LR C } \\
\text { Log } \\
\text { Pseu } \\
P<0\end{array}$ & $\begin{array}{l}07 \\
\text { hi-sq } \\
\text { like } \\
\text { do } \mathrm{R}^{2} \\
.01\end{array}$ & $\begin{array}{l}\text { are }=3 \\
\text { lood } \\
=0.19\end{array}$ & 56 & 37.366 \\
\hline
\end{tabular}


